\title{
Seasonality of respiratory syncytial virus in Buenos Aires. Relationship with global climate change
}

\author{
Fernando Ferrero, M.D., ${ }^{a}$ Fernando Torres, M.D., ${ }^{a}$ Rosana Abrutzky, B.S., María F. Ossorio, M.D., ${ }^{a}$ \\ Alejandra Marcos, M.D., ${ }^{c}$ Claudia Ferrario, M.D., ${ }^{d}$ and María J. Rial, M.D. ${ }^{e}$
}

\begin{abstract}
Introduction. Global climate change circulation pattern respiratory syncytial virus (RSV). We assessed whether RSV season has changed over the past 20 years and its correlation with mean annual temperature.

Methods. Cross-sectional study that included records of RSV and temperatures from Buenos Aires (1995-2014). RSV season onset, offset and duration, and its correlation with mean annual temperature were described for each year.

Results. A total of 8109 RSV infections were identified. The duration of RSV season reduced significantly (1995: 29 weeks vs. 2014: 17 weeks; R: 0.6; $p<0.001$ ) due to an early ending (1995: week 45 vs. 2014: week 33; R: 0.6; $p<0.001)$. No correlation was observed between mean annual temperature and RSV season start, end and duration.

Conclusion. Over the past 20 years, RSV season shortened significantly, butno correlation with temperature was observed. Key words: human respiratory syncytial virus, respiratory tract infections, climate change, global warming.
\end{abstract}

http:/ /dx.doi.org/10.5546/aap.2016.eng.52

\section{INTRODUCTION}

Acute respiratory infections are a major cause of morbidity and mortality, and respiratory syncytial virus (RSV) is the most common agent in children younger than 2 years old. ${ }^{1}$ Although the global burden of RSV is unknown, it has been estimated that between 66000 and 199000 children died in 2005 worldwide due to an acute respiratory infection associated with RSV. ${ }^{1}$

a. Department of Teaching and Research, Hospital General de Niños Pedro de Elizalde.

b. Instituto de Investigaciones Gino Germani, Facultad de Ciencias Sociales, Universidad de Buenos Aires.

c. Ministry of Health, Government of the City of Buenos Aires.

d. Department of Health Protection and Promotion.

e. Central Lab. Hospital General de Niños Pedro de Elizalde.

E-mailaddress:FernandoFerrero,M.D.PhD:fferrero@intramed.net

Funding: None.

Conflict of interest: None.

Received: 7-9-2015

Accepted: 8-19-2015
The season of RSV circulation varies depending on the region and its climate, and its onset and duration may change due to environmental conditions. ${ }^{2}$ In temperate climate zones, RSV circulates during the fall and winter, in association with lower temperatures and increased humidity. ${ }^{3}$

In the past years, the greenhouse effect has resulted in global warming and increased average temperatures. In the beginning of the $21^{\text {st }}$ century, the mean global temperature was $0.6{ }^{\circ} \mathrm{C}$ higher than that of the $20^{\text {th }}$ century. ${ }^{4} \mathrm{In}$ addition, a phenomenon known as the "urban heat island" has contributed to having higher local temperatures, a situation that has been extensively documented in the city of Buenos Aires. ${ }^{5}$

Such changes in local climate may have an impact on RSV circulation patterns. Thus, Donaldson has found in England that the RSV infection period has shortened in relation to higher temperatures. ${ }^{6}$

Knowledge of changes in RSV circulation patterns is essential to design specific health actions, which may even have an impact on the implementation of certain preventive measures, such as the administration of palivizumab. ${ }^{7}$

To date, there are no publications in our setting reviewing a likely relationship between climate change and modifications in RSV circulation. Our objective is to assess whether the duration of the RSV season has changed over the past 20 years and if the change in mean annual temperature is correlated to RSV season.

\section{MATERIAL AND METHODS}

This was a cross-sectional study using RSV identification records from a children's hospital located in the city of Buenos Aires between 1995 and 2014, ordered by epidemiological week (data from the hospital's Lab Department). Mean annual temperature records (in degrees Celsius) for the 1995-2014 period in the city of Buenos Aires were provided by the National Weather Service.

Outcome variables:

- Start of the RSV season: For each year, the first epidemiological week when the number 
of RSV cases identified is above $60 \%$ from the average weekly identifications for that year. ${ }^{6}$

- End of the RSV season: For each year, the first epidemiological week when the number of RSV cases identified is below $60 \%$ from the average weekly cases for that year. ${ }^{6}$

- Duration of the RSV season: For each year, the number of epidemiological weeks from start to end of the RSV season.

Statistical considerations: For each year, onset, offset and duration of the RSV season and mean annual temperature are described; variations in each parameter were assessed by simple linear regression. In addition, average values corresponding to the number of weeks of duration, start and end between both halves of the study period (1995-2004 vs. 2005-2014) were compared using Student's t test. The correlation between mean annual temperature and RSV season start and end (epidemiological week number) and between mean annual temperature and RSV season duration (in epidemiological weeks) was assessed using Pearson's correlation (P coefficient).

Ethical considerations: Data on temperature are publicly available. Data referred to RSV are absolutely dissociated from any personal information.

Institutional approval was requested and obtained (institutional review board and ethics committee). The study was registered at the Registro Público de investigaciones del Gobierno de la Ciudad de Buenos Aires (no. 467/14).

\section{RESULTS}

A total of 8109 cases of RSV were identified in the study period. Mean annual temperatures and start, end and duration of the RSV season were analyzed (Table 1).

RSV season started in week 17 both in 1995 and 2014 (the earliest onset week was week 11, while the latest one was week 20; median=17; R: 0.02; $p=0.4$ ).

RSV season ended in week 45 in 1995 and in week 33 in 2014 (the earliest ending week was week 28 , while the latest one was week 47 ; median $=39$; R: $0.6 ; p<0.001$ ).

RSV season lasted 29 weeks in 1995 and 17 weeks in 2014 (the shortest season lasted 15 weeks, while the longest one lasted 35 weeks; median= 24; R: 0.6; $p<0.001$ ) (Figure 1).

The comparison between the first half of the study period (1995-2004) and the second half (20052014) shows a shorter season duration (28.8 vs. 18.3 weeks; $p<0.001$ ) and an earlier end (week 42.5 vs. week $34.4 ; p<0.001$ ), with no differences in season start (week 15.56 vs. week 16.7; $p=0.2$ ).

Mean annual temperature was $17.8^{\circ} \mathrm{C}$ in 1995 and $18.3^{\circ} \mathrm{C}$ in 2014 , with a yearly average increase of $0.02{ }^{\circ} \mathrm{C}$ (R: $\left.0.04 ; p=0.2\right)$ (Figure 1 ).

TABLE 1. Season of circulation of respiratory syncytial virus and average annual temperature in the city of Buenos Aires

\begin{tabular}{|c|c|c|c|c|}
\hline \multirow[t]{2}{*}{ Year } & \multicolumn{3}{|c|}{ Season of circulation of respiratory syncytial virus } & \multirow[t]{2}{*}{ Mean annual temperature } \\
\hline & Start week & End week & Duration & \\
\hline 1995 & 17 & 45 & 29 & 17.8 \\
\hline 1996 & 20 & 47 & 28 & 18.3 \\
\hline 1997 & 13 & 39 & 27 & 18.5 \\
\hline 1998 & 17 & 46 & 30 & 17.8 \\
\hline 1999 & 11 & 40 & 35 & 17.7 \\
\hline 2000 & 12 & 39 & 29 & 17.7 \\
\hline 2001 & 16 & 47 & 24 & 18.4 \\
\hline 2002 & 16 & 40 & 32 & 18.0 \\
\hline 2003 & 18 & 46 & 24 & 17.7 \\
\hline 2004 & 17 & 36 & 30 & 18.1 \\
\hline 2005 & 18 & 38 & 21 & 17.9 \\
\hline 2006 & 17 & 39 & 19 & 18.2 \\
\hline 2007 & 17 & 33 & 17 & 17.4 \\
\hline 2008 & 18 & 36 & 19 & 18.5 \\
\hline 2009 & 17 & 39 & 23 & 18.2 \\
\hline 2010 & 14 & 28 & 15 & 18.2 \\
\hline 2011 & 14 & 30 & 17 & 17.9 \\
\hline 2012 & 17 & 32 & 16 & 18.3 \\
\hline 2013 & 18 & 36 & 19 & 18.1 \\
\hline 2014 & 17 & 33 & 17 & 18.3 \\
\hline
\end{tabular}


No correlation was observed between mean annual temperature and duration (P: $0.24 ; p=0.2)$, start (P: $0.2 ; p=0.4$ ) or end (P: $0.28 ; p=0.7)$ of the RSV season.

\section{DISCUSSION}

In most parts of the world, it has been verified that mean annual temperature has increased; in some regions, such increase was more than $2{ }^{\circ} \mathrm{C}$. In Argentina, the increase in temperature during the $20^{\text {th }}$ century was slightly below the global average; however, over the past decades, a trend towards extreme temperatures and heat waves has been confirmed. ${ }^{8}$

Environmental impact on health has been widely documented, especially in relation to climate and air pollution. Climate may have a more marked effect on respiratory diseases. ${ }^{9}$ It has been estimated that such environmental impact on health will gain much significance in the short term. ${ }^{10}$

Respiratory syncytial virus infection is one of the most common infections during childhood and has a remarkable health, financial and social impact worldwide. ${ }^{11}$

In spite of the fact that, in settings with appropiate access to the health system, RSV infection may be adequately managed, the extent of this condition implies a massive use of resources, making it mandatory to adequately plan strategies to fight RSV. ${ }^{12} \mathrm{~A}$ better understanding of factors determining virus circulation will help to improve effectiveness in terms of use of resources.

Particularly in relation to burdensome measures, such as the use of palivizumab, ${ }^{13}$ cost-effectiveness is a conclusive factor at the time of deciding its use. Recently, variations in this equation have been calculated based on different estimations of bronchiolitis mortality rates. ${ }^{14}$ Similarly, it is highly likely that a consistently shorter RSV season may warrant a modification in the number of monoclonal antibody doses, which may substantially improve the cost-effectiveness of this measure.

A limitation of this study is that it is restricted to only one site. However, data used in this study were obtained from a hospital that has participated in the National Epidemiological Surveillance System since its creation, its techniques are completely standardized, and most of its patients are from the community they represent.

In the study period, it was possible to verify a gradual shortening in the duration of RSV season at the expense of an increasingly earlier season ending. This is consistent with data reported by the United States Centers for Disease Control and Prevention (CDC) for the past years (RSV seasons that last, in average, 17 weeks).${ }^{15}$ However, the time series selected here (20 years) was short, so it is not possible to show significant differences in mean temperature. This may explain why it was not posible to demonstrate a correlation between an increase in temperature and a shorter duration of the RSV season. Considering that with slightly longer periods it is possible to verify significant changes in mean annual temperature, ${ }^{8}$ it is reasonable to believe that RSV data corresponding to a longer period would allow to obtain similar results to those described by Donaldson. ${ }^{6}$

FIGURE 1. Mean annual temperature and duration of the respiratory syncytial virus season, city of Buenos Aires, 1995-2014 period.

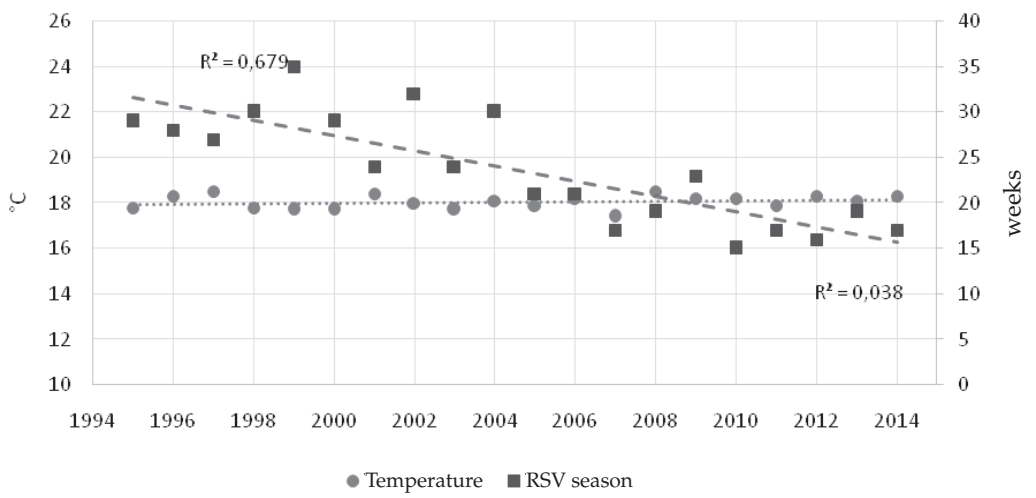




\section{CONCLUSION}

Over the past 20 years, RSV season has shortened significantly in the city of Buenos Aires. No correlation was observed between mean annual temperature and the duration, start or end of the RSV season.

\section{Acknowledgments}

To Irene Barnatán, B.S., Head of the Banco Nacional y Regional de Datos Meteorológicos y Ambientales, Servicio Meteorológico Nacional (Argentina), for granting access to data used in the study.

\section{REFERENCES}

1. Nair H, Nokes DJ, Gessner BD, Dherani M, et al. Global burden of acute lower respiratory infections due to respiratory syncytial virus in young children: a systematic review and meta-analysis. Lancet 2010;375(9725):1545-55.

2. Sloan C, Moore ML, Hartert T. Impact of pollution, climate, and sociodemographic factors on spatiotemporal dynamics of seasonal respiratory viruses. ClinTransl Sci 2011;4(1): 48-54.

3. Meerhoff TJ, Paget JW, Kimpen JL, Schellevis F. Variation of respiratory syncytial virus and the relation with meteorological factors in different winter seasons. Pediatr Infec Dis J 2009;28(10):860-6.

4. Mahishale V. Climate change and respiratory health: Time to act!! J Sci Soc 2014;41(3):149-50.

5. De Garín A, Bejarán R. Mortality rate and relative strain index in Buenos Aires city. Int I Biometeorol 2003;48(1):31-6.

6. Donaldson GC. Climate change and the end of the respiratory syncytial virus season. Clin Infect Dis 2006;42(5):677-9.

7. Murray J, Saxena S, Sharland M. Preventing severe respiratory syncytial virus disease: passive, active immunization and new antivirals. Arch Dis Child 2014;99(5):469-73.

8. Barros VR, Boninsegna JA, Camilloni IA, Chidiak M, et al. Climate change in Argentina: trends, projections, impacts and adaptation. Wiley Interdiscip Rev Clim Change 2015;6(2):151-69.

9. PaynterS, Ware RS, Weinstein P, WilliamsG, etal.Childhood pneumonia: a neglected, climate-sensitive disease? Lancet 2010;376(9755):1804-5.

10. Patz JA, Frumkin H, Holloway T, Vimont DJ, et al. Climate change: challenges and opportunities for global health. JAMA 2014;312(15):1565-80.

11. Díez-Domingo J, Pérez-Yarza EG, Melero JA, SánchezLuna M, et al. Social, economic, and health impact of the respiratory syncytial virus: a systematic search. BMC Infect Dis 2014;14:544.

12. Byington CL, Wilkes J, Korgenski K, Sheng X. Respiratory syncytial virus-associated mortality in hospitalized infants and young children. Pediatrics 2015;135(1):e24-31.

13. American Academy of Pediatrics Committee on Infectious Diseases, American Academy of Pediatrics Bronchiolitis Guidelines Committee. Updated guidance for palivizumab prophylaxis among infants and young children at increased risk of hospitalization for respiratory syncytial virus infection. Pediatrics 2014;134(2):415-20.

14. Andabaka T, Nickerson JW, Rojas-Reyes MX, Rueda JD, et al. Monoclonal antibody for reducing the risk of respiratory syncytial virus infection in children. Cochrane Database Syst Rev 2013:4:CD006602.

15. Centers for Disease Control and Prevention. Respiratory syncytial virus activity: United States, July 2007-December 2008. MMWR Morb Mortal Wkly Rep 2008;57(50):1355-8. 